Case Report

\title{
Lymphoepithelioma-Like Carcinoma of the Breast: A Case Report Unveiling Several Clinical and Histopathological Challenges
}

\author{
Tarek Aridi, ${ }^{1}$ Mohamad Fawwaz, ${ }^{2,3}$ Ahmad Kassab, ${ }^{2,3}$ Marwan Bahmad, ${ }^{2,3}$ \\ Faisal Houcheimi, ${ }^{2,3}$ Mohamad Mshiek, ${ }^{2,3}$ Fouad Boulos ${ }^{1},{ }^{4}$ Ali Kanj, ${ }^{5}$ Ghassan Ramadan, ${ }^{3}$ \\ Hisham F. Bahmad $\mathbb{D}^{6},{ }^{6}$ and Najla Fakhruddin $\mathbb{D}^{4,7}$ \\ ${ }^{1}$ Faculty of Medicine, American University of Beirut, Beirut, Lebanon \\ ${ }^{2}$ Faculty of Medicine, Beirut Arab University, Beirut, Lebanon \\ ${ }^{3}$ Department of General Surgery, Hammoud Hospital University Medical Center, Saida, Lebanon \\ ${ }^{4}$ Department of Pathology and Laboratory Medicine, American University of Beirut Medical Center, Beirut, Lebanon \\ ${ }^{5}$ Department of Radiology, Hammoud Hospital University Medical Center, Saida, Lebanon \\ ${ }^{6}$ Department of Anatomy, Cell Biology and Physiological Sciences, Faculty of Medicine, American University of Beirut, \\ Beirut, Lebanon \\ ${ }^{7}$ Department of Pathology, Hammoud Hospital University Medical Center, Saida, Lebanon
}

Correspondence should be addressed to Hisham F. Bahmad; hfbahmad@gmail.com and Najla Fakhruddin; nf21@aub.edu.lb

Received 17 April 2018; Accepted 7 June 2018; Published 12 July 2018

Academic Editor: Piergiuseppe Colombo

Copyright (C) 2018 Tarek Aridi et al. This is an open access article distributed under the Creative Commons Attribution License, which permits unrestricted use, distribution, and reproduction in any medium, provided the original work is properly cited.

\begin{abstract}
Lymphoepithelioma-like carcinoma (LELC) of the breast is an extremely rare tumor type. Histologically, it mimics undifferentiated nasopharyngeal carcinoma by demonstrating nests of neoplastic epithelial cells in a background of lymphoplasmacytic infiltrates. This paper reports a 62 -year-old female patient with a $3 \times 1.5 \mathrm{~cm}$ BI-RADS type IV breast mass diagnosed on excisional biopsy as LELC. The tumor is negative for estrogen and progesterone receptors and did not overexpress HER2/neu. Routine tests for clearance before surgery were performed, and patient was managed by a modified radical mastectomy with axillary lymph node dissection showing no residual tumor. Surgical CAse REports (SCARE) guidelines were followed for reporting our case. The rarity of LELC of the breast warrants the establishment and implementation of well-defined guidelines and criteria for diagnosis and management.
\end{abstract}

\section{Introduction}

Lymphoepithelioma-like carcinoma (LELC) of the breast is an extremely rare malignancy with 32 cases reported in the world literature to date [1]. In 1994, Kumar and Kumar described the first case of LELC in the breast of a 65 -year-old woman, in which utilizing immunostaining of the tumor sections revealed scanty epithelial neoplastic cells with copious lymphocytic infiltrates [2]. Morphologically, the tumor resembled nasopharyngeal lymphoepithelioma (old terminology for undifferentiated nasopharyngeal carcinoma) and other similar tumors occurring in different organs such as the stomach, salivary glands, lungs, thyroid, and uterus [3].
Histologically, LELC of the breast is characterized by ill-defined cohesive nests of malignant epithelial cells within a background of dense and diffuse lymphoid infiltration that is intimately mixed with the tumor $[1,3]$. Although EpsteinBarr virus (EBV) has been linked to the pathogenesis of LELC of the nasopharynx, salivary glands, stomach, and others, it has never been associated with breast LELCs $[1,4]$.

In this paper, we present a case of LELC of the breast, with a minireview of the literature. We also describe the differential diagnoses and the therapeutic approaches that have been adopted in the treatment of this tumor. This surgical case report (Figure 1) was conducted and reported in accordance with Surgical CAse REports (SCARE) guidelines for reporting case reports. 
62-year-old female, with history of hypertension

Chief complaint: burning sensation in left breast

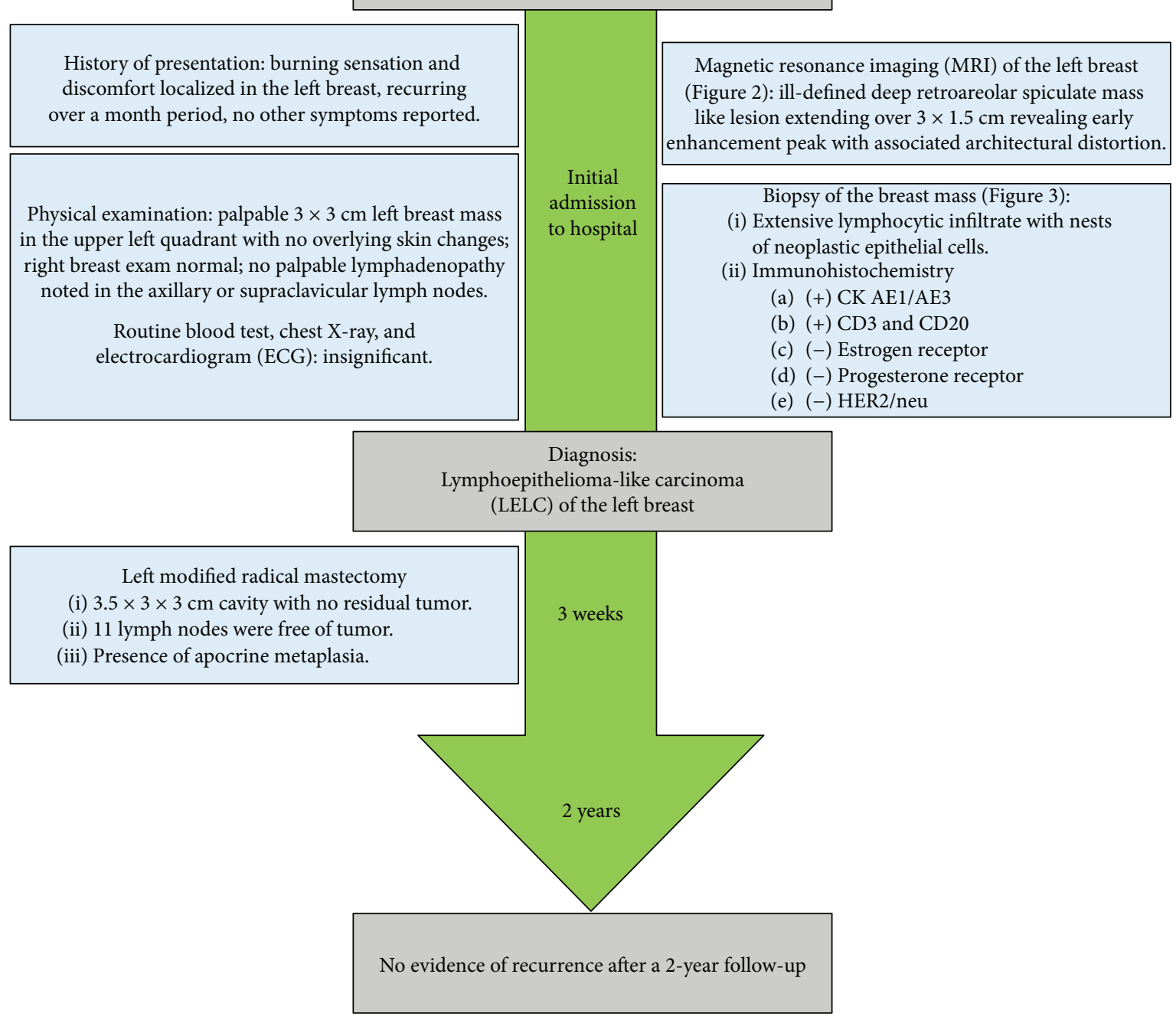

Figure 1: Timeline organizing main events of the case.

\section{Case Presentation}

A 62-year-old female patient who is heavy smoker presented with a burning sensation and discomfort in her left breast that has been recurring over a month prior to admission to the hospital. No fever, chills, or any other symptoms were described. She reported a past medical history of hypertension and a surgical history of hemorrhoidectomy, dilation and curettage surgery, colonoscopy, and gastroscopy.

Physical examination revealed a palpable left breast mass (measuring approximately $3 \times 3 \mathrm{~cm}$ ) in the upper quadrant with no overlying skin changes. The right breast exam was normal. No palpable locoregional lymphadenopathy (axilla and supraclavicular lymph nodes) was noticed. Routine blood tests (complete blood count with differential, electrolytes, prothrombin time, partial prothrombin time, and international normalized ratio), chest X-ray, and electrocardiogram (ECG) were all normal.
Magnetic resonance imaging (MRI) of the left breast showed an ill-defined deep retroareolar spiculate lesion extending over $3 \times 1.5 \mathrm{~cm}$ revealing early enhancement peak with associated architectural distortion. There were no axillary lymph nodes or abnormal bone signal intensity. No cutaneous thickening or retraction was seen. Findings were suggestive of BIRADS type IV lesion (Figure 2).

An excisional biopsy was performed and revealed breast tissue with extensive lymphocytic infiltrate intermixed with neoplastic epithelial cells (Figure 3). Immunohistochemistry results were positive for $\mathrm{CK}$ AE1/E3 antibody in the neoplastic epithelial cells with no expression of estrogen or progesterone receptors, and HER2/neu was not overexpressed (Figure 4(c)). The lymphocytes in the background stained positive for both CD3 and CD20 (Figures 4(a) and 4(b)).

The patient underwent a left modified radical mastectomy. Eleven lymph nodes were dissected and free of tumor. The mastectomy specimen showed a $3.5 \times 3 \times 3 \mathrm{~cm}$ cavity at 

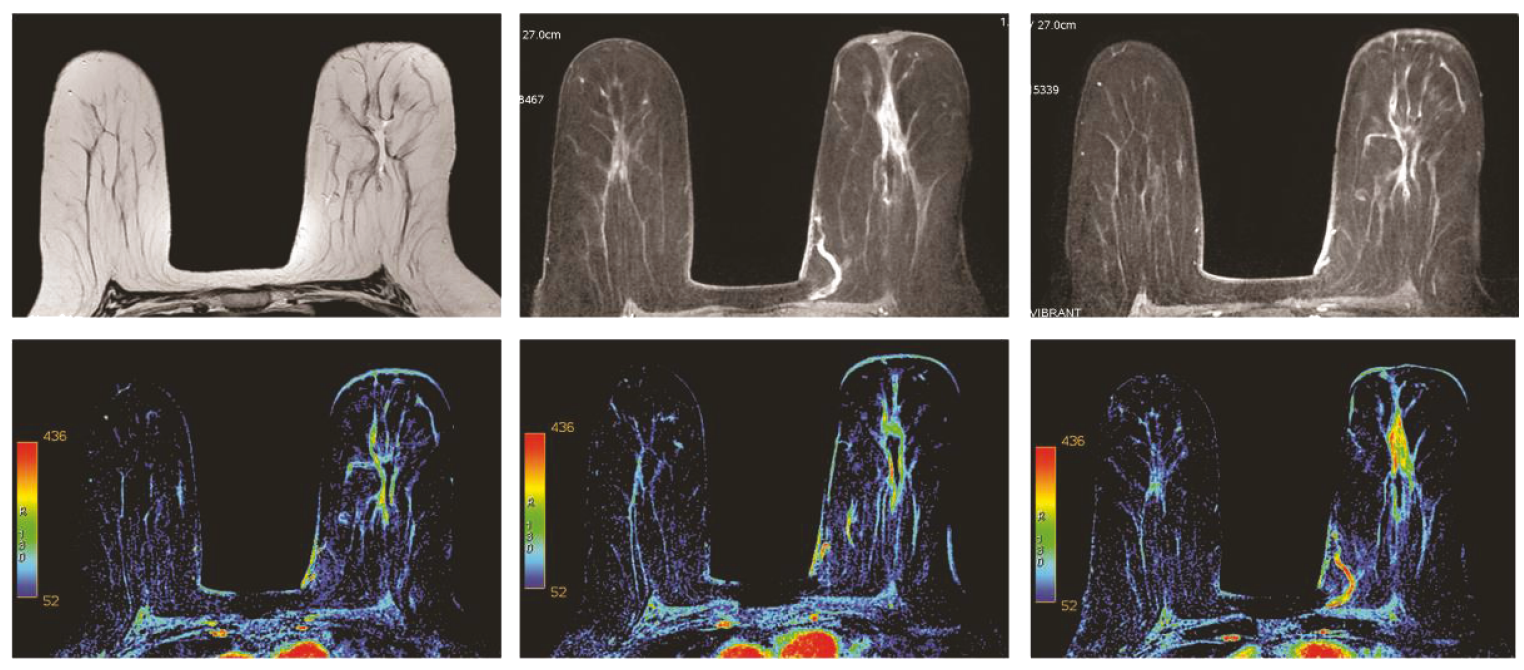

FIGURE 2: Breast MRI. Ill-defined deep retroareolar spiculate mass-like lesion extending over $3 \times 1.5 \mathrm{~cm}$ revealing early enhancement peak with associated architectural distortion.

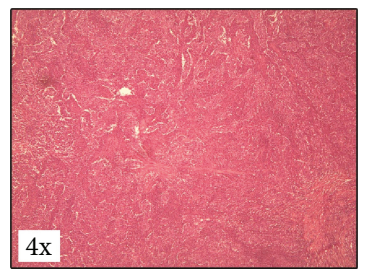

(a)

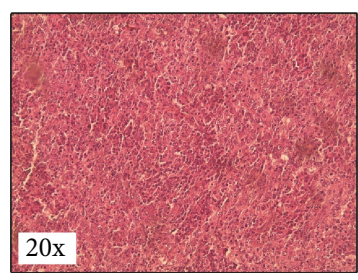

(c)

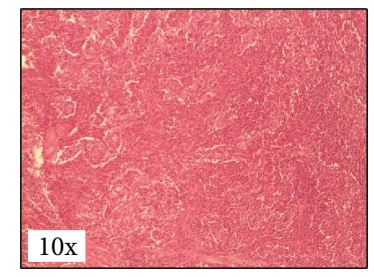

(b)

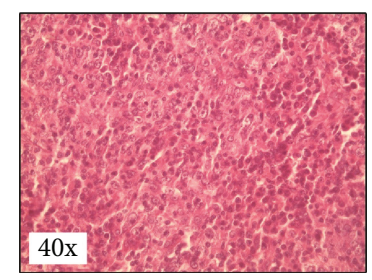

(d)

FIgURE 3: ( $\mathrm{a}$ and b) Low magnification histopathological examination of the breast tumor demonstrating nests of neoplastic epithelial cells in a background of dense lymphocytic infiltrate. ( $c$ and $d$ ) Higher magnification showing the tumor cells with abundant pale cytoplasm, large vesicular nuclei, and prominent nucleolus (hematoxylin and eosin stain).

the site of the previous excisional biopsy. On histological examination, apocrine metaplasia was identified but no residual tumor was detected. To note, apocrine metaplasia is a very common incidental benign finding that is considered part of or associated with fibrocystic changes, and hence, does not affect prognosis and management [5]. Accordingly, no adjuvant hormonal therapy, chemotherapy, or radiotherapy was given to the patient.

No evidence of recurrence was noted on a 2-year follow-up.

\section{Discussion}

Lymphoepithelioma-like carcinomas (LELCs) are a type of malignant tumors that can be found in any organ with an epithelial tissue origin such as the lungs, urinary bladder, thymus, colon, skin, prostate, and breast [6]. Microscopically, they mimic undifferentiated nasopharyngeal carcinoma which is known to be strongly associated with Epstein-Barr virus (EBV) infection. Similarly, LELCs of the thymus, salivary glands, lungs, and stomach are associated with EBV infection as demonstrated by Iezzoni et al. [4]. To our knowledge, none of the reported LELCs of the breast were associated with EBV infection (Table 1). Human papilloma virus (HPV) has been detected in two LELCs of the breast $[3,7]$, but Herrera-Goepfert et al. considered that the HPV viral load in breast neoplasms proved to be really low thus excluding its involvement in the carcinogenesis [8]. Therefore, based on current evidence, the etiology of LELC of the breast cannot be correlated with viral infection.

LELC of the breast is a rare histopathologic variant of breast carcinoma and is not a part of the World Health 


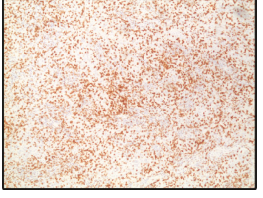

CD3

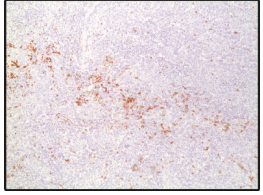

CD2

(b)

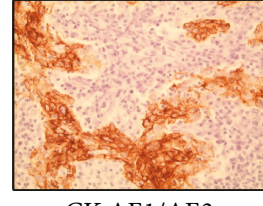

(c)

FIgURE 4: The lymphocytes show positive immunohistochemical staining for CD3 (a), CD20 (b), and the tumor cell-positive immunohistochemical staining for cytokeratin AE1/AE3 (c).

TABLE 1: Table summarizing main clinicopathological parameters of LELC cases reported so far in world literature.

\begin{tabular}{|c|c|c|c|c|c|c|c|c|c|c|}
\hline Number & Authors and reference & Year & $\begin{array}{c}\text { Patient age } \\
\text { (years) }\end{array}$ & $\begin{array}{c}\text { Tumor size } \\
(\mathrm{cm})\end{array}$ & $\begin{array}{l}\text { Lymph } \\
\text { node }\end{array}$ & ER & $\mathrm{PR}$ & Her2 & $\begin{array}{c}\text { CK AE1/ } \\
\text { AE3 }\end{array}$ & EBV \\
\hline 1 & Kumar and Kumar [2] & 1994 & 65 & 2.0 & 0 & + & + & - & + & - \\
\hline 2 & Cristina et al. [17] & 2000 & 54 & 1.5 & $0 / 19$ & $+(42 \%)$ & $-(<10 \%)$ & - & NA & - \\
\hline 3 & \multirow{6}{*}{ Dadmanesh et al. [14] } & \multirow{6}{*}{2001} & 43 & 1.9 & $1 / 1$ & - & - & - & NA & - \\
\hline 4 & & & 53 & 2.0 & & - & - & - & NA & - \\
\hline 5 & & & 49 & 1.0 & $0 / 19$ & - & - & - & NA & - \\
\hline 6 & & & 52 & 2.7 & $0 / 20$ & + & - & - & NA & - \\
\hline 7 & & & 64 & 2.0 & $0 / 29$ & - & - & - & NA & - \\
\hline 8 & & & 69 & 2.3 & $0 / 19$ & - & - & - & NA & - \\
\hline 9 & Naidoo and Chetty [18] & 2001 & 50 & 2.5 & $2 / 24$ & NA & NA & NA & - & - \\
\hline 10 & Pestereli et al. [19] & 2002 & 56 & 2.0 & $2 / 27$ & + & + & - & + & - \\
\hline 11 & Sanati et al. [11] & 2004 & 62 & 3.0 & NA & $+(10 \%)$ & - & - & + & - \\
\hline 12 & \multirow{2}{*}{ Ilvan et al. [16] } & \multirow{2}{*}{2004} & 59 & 3.5 & $0 / 20$ & + & + & - & + & - \\
\hline 13 & & & 67 & 1.1 & $0 / 16$ & - & - & - & + & - \\
\hline 14 & Kurose et al. [20] & 2005 & 47 & 2.8 & $0 / 33$ & - & - & + & + & - \\
\hline 15 & Saleh et al. [12] & 2005 & 51 & 1.3 & $1 / 8$ & - & - & NA & + & - \\
\hline 16 & Kulka et al. [7] & 2008 & 42 & 2.5 & $0 / 10$ & + & - & - & + & - \\
\hline 17 & O’Sullivan-Mejia et al. [21] & 2009 & 55 & 3.1 & $0 / 2$ & - & - & + & + & - \\
\hline 18 & Jeong et al. [22] & 2010 & 37 & 3.0 & $0 / 13$ & - & - & + & + & - \\
\hline 19 & Dinniwell et al. [6] & 2012 & 55 & 4.0 & $0 / 2$ & - & - & - & NA & - \\
\hline 20 & Nio et al. [3] & 2012 & 45 & 3.0 & $0 / 5$ & - & - & - & NA & NA \\
\hline 21 & Suzuki et al. [23] & 2012 & 64 & 2.1 & $3 / 23$ & - & - & + & NA & NA \\
\hline 22 & Trihia et al. [24] & 2012 & 53 & 1.5 & $2 / 30$ & - & - & + & + & NA \\
\hline 23 & Abdou and Asaad [13] & 2014 & 45 & 2.0 & $0 / 24$ & - & - & - & NA & - \\
\hline 24 & Top et al. [25] & 2014 & 59 & 3.0 & $0 / 23$ & - & - & - & NA & - \\
\hline 25 & Nankin et al. [26] & 2015 & 39 & 2.7 & $0 / 5$ & $+(40 \%)$ & - & - & NA & NA \\
\hline 26 & Sato et al. [27] & 2016 & 50 & 1.2 & $1 / 23$ & - & - & - & + & - \\
\hline 27 & Herrera-Goepfert et al. [28] & 2016 & 57 & 4.0 & 0 & + & + & - & + & - \\
\hline 28 & & & 56 & 3.0 & $1 / 17$ & - & - & - & NA & - \\
\hline 29 & & & 39 & 2.0 & $0 / 18$ & - & - & - & NA & - \\
\hline 30 & Shet et al. [1] & 2016 & 40 & 2.5 & NA & - & - & - & NA & - \\
\hline 31 & & & 40 & 3.5 & NA & - & - & - & NA & - \\
\hline 32 & & & 51 & 3.0 & NA & - & - & - & NA & - \\
\hline 33 & Present case & 2017 & 62 & 3.5 & $0 / 11$ & - & - & - & + & NA \\
\hline
\end{tabular}

ER: estrogen receptor; PR: progesterone receptor; Her2: Her2 receptor; CK: cytokeratin; EBV: Epstein-Barr virus; NA: not available.

Organization (WHO) classification for breast cancer [9]. To the best of our knowledge, only 33 cases were published in the English literature until drafting this case.
The average patient age is 52 years (range: 37 to 69 years). The tumors have an average diameter of $2.5 \mathrm{~cm}$ (range: 1 to $4 \mathrm{~cm}$ ). Metastasis to lymph nodes was observed in $29 \%$ of 
the cases ( 8 out of 28 examined cases), a finding consistent with their relatively favorable prognosis. Estrogen receptors were expressed in $28 \%$ of the cases while progesterone receptors were expressed in $13 \%$ of the cases. Majority of the cases with lymph node involvement (7 out of 8 cases) were negative for estrogen and progesterone receptors, while $16 \%$ (5 out of 31 cases) overexpressed HER2/neu (Table 1).

Although in most cases of breast lesions, mammography is usually the primary imaging modality used, recent studies have been emphasizing on the efficacy of MRI over mammography in detecting and assessing such breast lesions. In one study by Roganovic et al., it has been shown that "sensitivity for digital mammography, breast MRI, and breast tomosynthesis was $72.4 \%, 93.1 \%$, and $100 \%$, respectively, while the specificity was $46.4 \%, 60.7 \%$, and $75 \%$, respectively" [10].

In order to avoid misdiagnosis of LELC of the breast, it is important to consider neoplasms of the breast with evident lymphocytic infiltrate, such as lymphomas and medullary carcinomas, in the differential diagnosis. A reported case of LELC was originally misdiagnosed as lymphoma or pseudolymphoma as a result of a dense lymphocytic component concealing the elusive neoplastic cells [11]. Another case of LELC of the breast mimicked sclerosing Hodgkin's lymphoma with a tumor section comprising nodular clusters of lymphocytic cells interspersed around a network of fibrous septae [12]. This necessitates the use of a panel of immunohistochemical markers with cytokeratin and leukocyte common antigen, to differentiate between lymphomas and lymphoepithelioma-like carcinomas [13]. LELC of the breast and medullary carcinomas share the presence of syncytial growth patterns, a dense lymphocytic infiltrate, and the absence of estrogen receptors $[11,14]$. However, they vary grossly, with the medullary carcinoma being well circumscribed and demarcated as compared to LELC of the breast, and microscopically, with the medullary carcinomas' syncytial growth patterns covering an area greater than 75\% [15]. Moreover, the lymphocytic component in medullary carcinoma does not obscure the epithelial component as extensively as it does in LELC of the breast [16]. Immunohistochemically, medullary carcinomas are usually E-cadherin positive, while LELC of the breast are negative [11].

Currently, there is no standard protocol for the treatment of LELC of the breast, due to the rarity of this tumor; nevertheless, several methods have been adopted. Radical or partial mastectomy is the most common practiced surgical procedure in all reported cases of LELC of the breast. In our case, modified radical mastectomy of the left breast with axillary lymph node dissection was performed. Moreover, many of the reported cases have received adjuvant chemotherapy and radiotherapy, while hormonal therapy was used for patients with positive estrogen or progesterone receptors.

Although there are a limited number of cases to evaluate the prognosis of LELCs of the breast, it is important to note that after years of follow-up, the majority (27 out of 33) had no evidence of recurrence or metastasis postsurgery and therapy. Therefore, LELC of the breast can be considered to have a favorable prognosis. No molecular characterization of LELC of the breast has been reported yet. Therefore, further studies are needed to better characterize this tumor and may provide an optimal therapeutic protocol for LELCs of the breast in the future. In addition, it is strongly recommended to include LELC as a part of the WHO classification for breast cancer, which may consequently aid in correlating clinicopathological findings associated with LELC with the classic histopathological classification of breast cancer.

\section{Concluding Remarks}

Lymphoepithelioma-like carcinoma of the breast is an extremely rare entity with a favorable outcome when treated; therefore, it should be considered when diagnosing breast tumors with a rich lymphocytic infiltrate. Sometimes LELC of the breast maybe misdiagnosed as lymphoma or as medullary carcinomas. Accurate diagnosis can be attained with good evaluation of the morphology and correlation with immunohistochemistry findings. We expect to see more cases of LELC of the breast reported in the literature; therefore, well-defined guidelines and criteria for diagnosis and management of an LELC in the breast are warranted.

\section{Abbreviations \\ BI-RADS: Breast imaging reporting and data system \\ EBV: $\quad$ Epstein-Barr virus \\ ECG: $\quad$ Electrocardiogram \\ HPV: Human papilloma virus \\ LELC: Lymphoepithelioma-like carcinoma \\ MRI: $\quad$ Magnetic resonance imaging \\ SCARE: $\quad$ Surgical CAse REports \\ WHO: World Health Organization.}

\section{Ethical Approval}

This case report was carried out in accordance with the recommendations of the Institutional Review Boards (IRB) of Hammoud Hospital University Medical Center and Beirut Arab University with written informed consent from the included subject. The patient gave written informed consent in accordance with the Declaration of Helsinki. Written informed consent was obtained from the patient for publication of this case report and accompanying images. A copy of the written consent is available upon request for review by the Editor-in-Chief of this journal.

\section{Conflicts of Interest}

The authors declare that the research was conducted in the absence of any commercial or financial relationships that could be construed as a potential conflict of interest.

\section{Authors' Contributions}

Tarek Aridi, Hisham F. Bahmad, and Najla Fakhruddin worked on study conception and design. Ghassan Ramadan is the attending surgeon who operated the case. Tarek Aridi and Hisham F. Bahmad developed the search strategy. Mohamad Fawwaz, Ahmad Kassab, and Marwan Bahmad screened titles for relevance and abstracted the data from 
the eligible full-text articles. Faisal Houcheimi and Mohamad Mshiek were responsible for reporting the clinical course of the case. Najla Fakhruddin worked on the histology figures and performed the molecular analysis experiments and molecular data analyses. Fouad Boulos and Ali Kanj provided other authors with explanations about the case reported. Tarek Aridi and Hisham F. Bahmad worked on the figures' illustrations and presentation of the case study timeline. Tarek Aridi, Hisham F. Bahmad, and Najla Fakhruddin analyzed the data and drafted the manuscript. Tarek Aridi, Hisham F. Bahmad, Najla Fakhruddin, and Fouad Boulos critically revised and edited the manuscript. All authors have read and approved the final draft.

\section{Acknowledgments}

The authors would like to thank the family of the patient whose case is presented here for granting their permission to publish this case report and Hammoud Hospital University Medical Center for their permission to disclose this information.

\section{References}

[1] T. Shet, T. Pai, O. Shetty, and S. Desai, "Lymphoepitheliomalike carcinoma of breast-evaluation for Epstein-Barr virusencoded RNA, human papillomavirus, and markers of basal cell differentiation," Annals of Diagnostic Pathology, vol. 25, pp. 42-47, 2016.

[2] S. Kumar and D. Kumar, "Lymphoepithelioma-like carcinoma of the breast," Modern Pathology, vol. 7, no. 1, pp. 129-131, 1994.

[3] Y. Nio, K. Tsuboi, M. Tamaoki, M. Tamaoki, and R. Maruyama, "Lymphoepithelioma-like carcinoma of the breast: a case report with a special analysis of an association with human papilloma virus," Anticancer Research, vol. 32, no. 4, pp. 1435-1441, 2012.

[4] J. C. Iezzoni, M. J. Gaffey, and L. M. Weiss, "The role of Epstein-Barr virus in lymphoepithelioma-like carcinomas," American Journal of Clinical Pathology, vol. 103, no. 3, pp. 308-315, 1995.

[5] Y. Gao, V. Dialani, C. DeBenedectis, N. Johnson, E. Brachtel, and P. Slanetz, "Apocrine metaplasia found at MR biopsy: is there something to be learned?," The Breast Journal, vol. 23, no. 4, pp. 429-435, 2017.

[6] R. Dinniwell, W. M. Hanna, M. Mashhour, R. S. Saad, and G. J. Czarnota, "Lymphoepithelioma-like carcinoma of the breast: a diagnostic and therapeutic challenge," Current Oncology, vol. 19, no. 3, pp. e177-e183, 2012.

[7] J. Kulka, I. Kovalszky, E. Svastics, M. Berta, and T. Füle, "Lymphoepithelioma-like carcinoma of the breast: not Epstein-Barr virus-, but human papilloma virus-positive," Human Pathology, vol. 39, no. 2, pp. 298-301, 2008.

[8] R. Herrera-Goepfert, N. A. Khan, C. Koriyama, S. Akiba, and V. M. Pérez-Sánchez, "High-risk human papillomavirus in mammary gland carcinomas and non-neoplastic tissues of Mexican women: no evidence supporting a cause and effect relationship," Breast, vol. 20, no. 2, pp. 184-189, 2011.

[9] S. R. Lakhani, WHO Classification of Tumours of the Breast, International Agency for Research on Cancer, 2012.
[10] D. Roganovic, D. Djilas, S. Vujnovic, D. Pavic, and D. Stojanov, "Breast MRI, digital mammography and breast tomosynthesis: comparison of three methods for early detection of breast cancer," Bosnian Journal of Basic Medical Sciences, vol. 15, no. 4, pp. 64-68, 2015.

[11] S. Sanati, A. G. Ayala, and L. P. Middleton, "Lymphoepithelioma-like carcinoma of the breast: report of a case mimicking lymphoma," Annals of Diagnostic Pathology, vol. 8, no. 5, pp. 309-315, 2004.

[12] R.'a. Saleh, P. DaCamara, J. Radhi, and O. Boutross-Tadross, "Lymphoepithelioma-like carcinoma of the breast mimicking nodular sclerosing Hodgkin's lymphoma," The Breast Journal, vol. 11, no. 5, pp. 353-354, 2005.

[13] A. G. Abdou and N. Y. Asaad, "Lymphoepithelioma-like carcinoma of the breast: cytological, histological, and immunohistochemical characteristics," Diagnostic Cytopathology, vol. 43, no. 3, pp. 210-3, 2015.

[14] F. Dadmanesh, J. L. Peterse, A. Sapino, A. Fonelli, and V. Eusebi, "Lymphoepithelioma-like carcinoma of the breast: lack of evidence of Epstein-Barr virus infection," Histopathology, vol. 38, no. 1, pp. 54-61, 2001.

[15] R. L. Ridolfi, P. P. Rosen, A. Port, D. Kinne, and V. Miké, "Medullary carcinoma of the breast: a clinicopathologic study with 10 year follow-up," Cancer, vol. 40, no. 4, pp. 13651385, 1977.

[16] S. Ilvan, V. Celik, E. Ulker Akyildiz, N. Senel Bese, R. Ramazanoglu, and Z. Calay, "Lymphoepithelioma-like carcinoma of the breast: is it a distinct entity? Clinicopathological evaluation of two cases and review of the literature," Breast, vol. 13, no. 6, pp. 522-6, 2004.

[17] S. Cristina, R. Boldorini, F. Brustia, and G. Monga, "Lymphoepithelioma-like carcinoma of the breast. An unusual pattern of infiltrating lobular carcinoma," Virchows Archiv, vol. 437, no. 2, pp. 198-202, 2000.

[18] P. Naidoo and R. Chetty, "Lymphoepithelioma-like carcinoma of the breast with associated sclerosing lymphocytic lobulitis," Archives of Pathology \& Laboratory Medicine, vol. 125, no. 5, pp. 669-672, 2001.

[19] H. E. Pestereli, O. Erdogan, R. Kaya, and F. S. Karaveli, "Lymphoepithelioma-like carcinoma of the breast," APMIS, vol. 110, no. 6, pp. 447-450, 2002.

[20] A. Kurose, R. Ichinohasama, H. Kanno et al., "Lymphoepithelioma-like carcinoma of the breast. Report of a case with the first electron microscopic study and review of the literature," Virchows Archiv, vol. 447, no. 3, pp. 653-659, 2005.

[21] E. O'Sullivan-Mejia, M. O. Idowu, H. Davis Masssey, G. Cardenosa, and M. M. Grimes, "Lymphoepithelioma-like carcinoma of the breast: diagnosis by core needle biopsy," The Breast Journal, vol. 15, no. 6, pp. 658-660, 2009.

[22] A. K. Jeong, S. B. Park, Y. M. Kim et al., "Lymphoepitheliomalike carcinoma of the breast," Journal of Ultrasound in Medicine, vol. 29, no. 3, pp. 485-488, 2010.

[23] I. Suzuki, P. Chakkabat, L. Goicochea, C. Campassi, and S. Chumsri, "Lymphoepithelioma-like carcinoma of the breast presenting as breast abscess," World Journal of Clinical Oncology, vol. 5, no. 5, pp. 1107-1112, 2014.

[24] H. Trihia, H. Siatra, H. Gklisty, P. Diamantopoulos, P. Arapantoni-Dadiotis, and K. Kalogerakos, "Lymphoepithelioma-like carcinoma of the breast: cytological and histological features and review of the literature," Acta Cytologica, vol. 56, no. 1, pp. 85-91, 2012. 
[25] O. E. Top, E. Vardar, A. Yagci, S. Deniz, R. Ozturk, and B. Zengel, "Lymphoepithelioma-like carcinoma of the breast: a case report," The Journal of Breast Health, vol. 10, no. 3, pp. 177-180, 2014.

[26] N. L. Nankin, C. J. Gondusky, P. A. Abasolo, and B. N. Kalantari, "Lymphoepithelioma-like carcinoma of the breast," Radiology Case Reports, vol. 10, no. 1, p. 963, 2015.

[27] A. Sato, T. Kawasaki, A. Abo-Yashima et al., "Cytological features of lymphoepithelioma-like carcinoma of the breast," Cytopathology, vol. 28, no. 2, pp. 169-172, 2017.

[28] R. Herrera-Goepfert, C. Caro-Sánchez, and E. Maafs-Molina, "Lymphoepithelioma-like carcinoma of the breast: a singular morphological pattern with an expected outcome," Austin Journal of Clinical Case Reports, vol. 3, no. 4, p. 1102, 2016. 


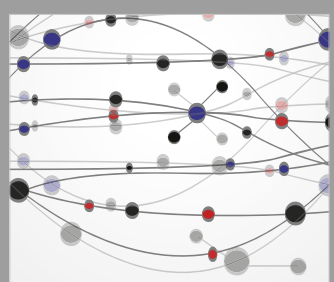

The Scientific World Journal
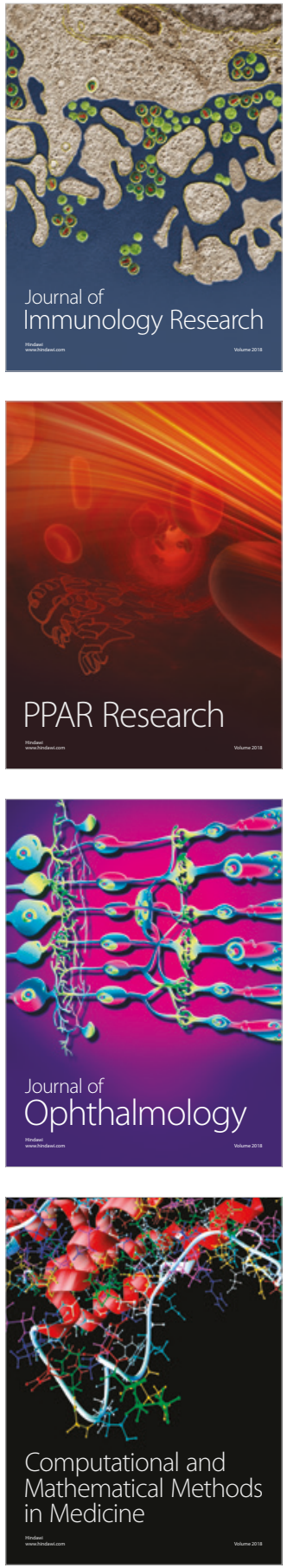

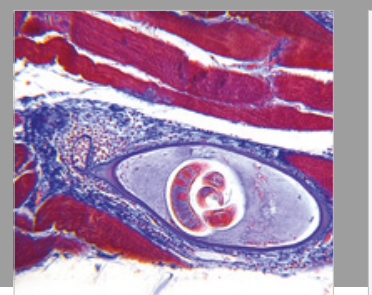

Gastroenterology Research and Practice

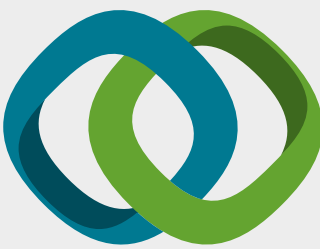

\section{Hindawi}

Submit your manuscripts at

www.hindawi.com
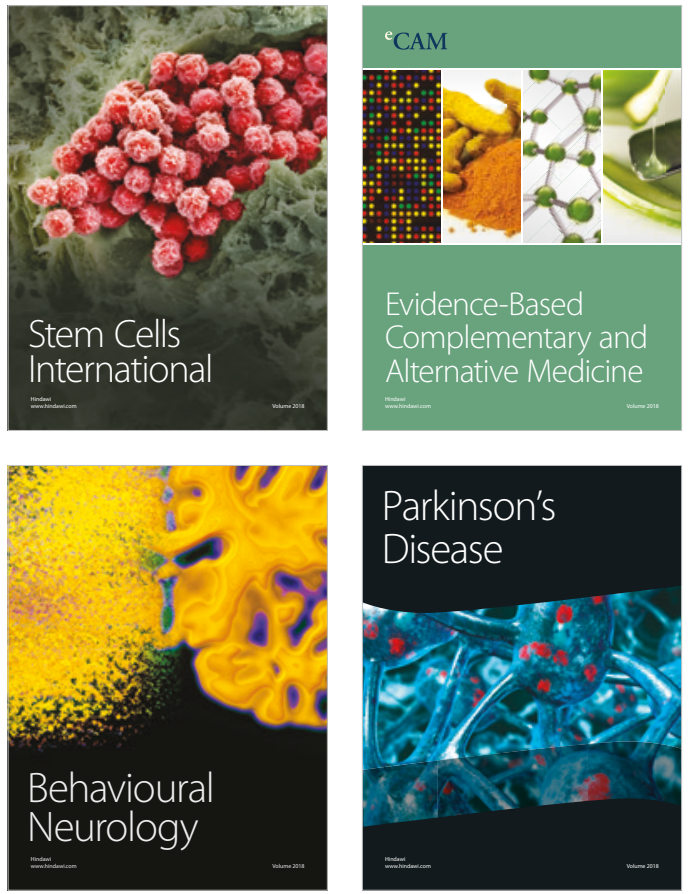

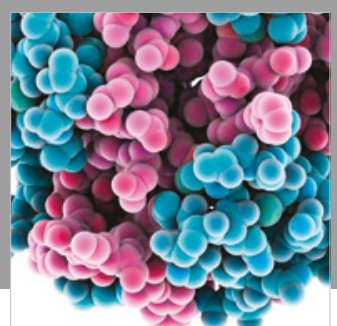

ournal of

Diabetes Research

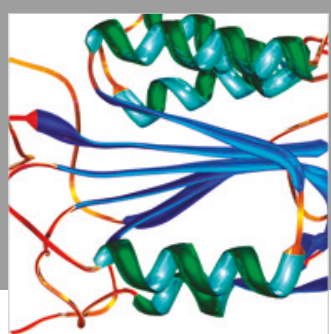

Disease Markers
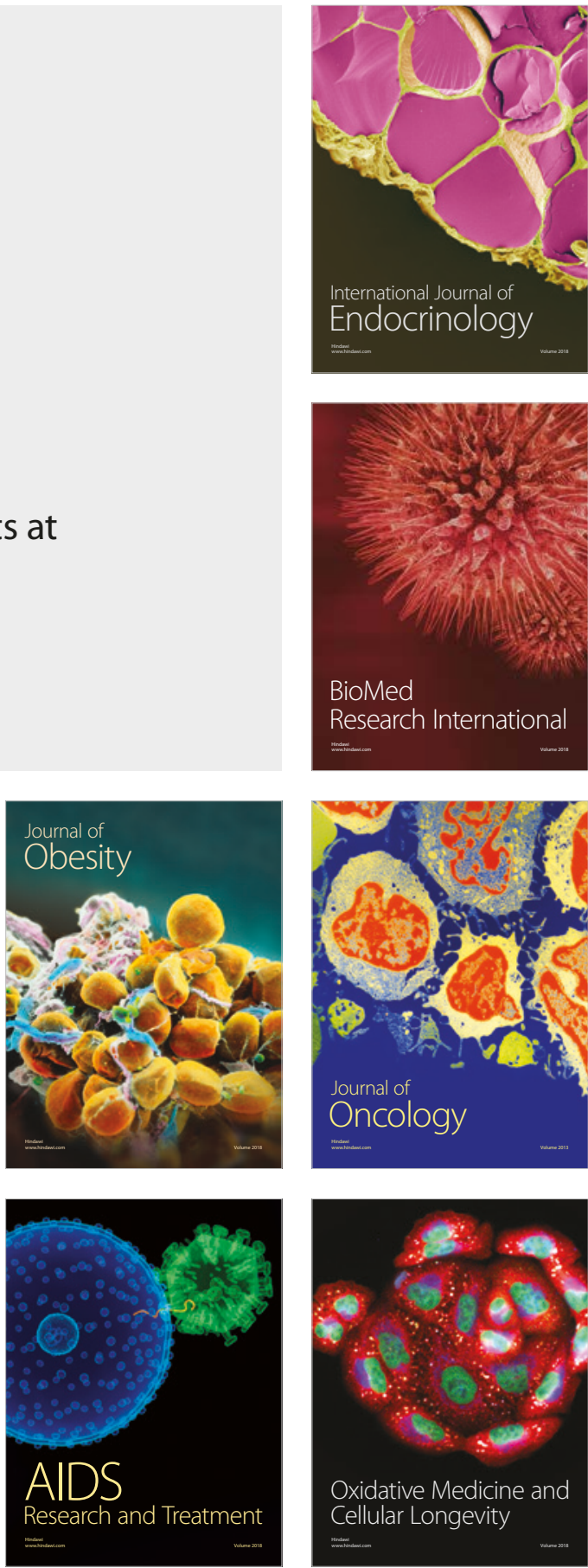